\title{
Editorial
}

\section{Analytical Chemistry and Innovative Applications}

\author{
Marcello Locatelli (D)
}

check for updates

Citation: Locatelli, M. Analytical

Chemistry and Innovative

Applications. Analytica 2021, 2, 37.

https://doi.org/10.3390/

analytica2020004

Received: 9 April 2021

Accepted: 25 April 2021

Published: 29 April 2021

Publisher's Note: MDPI stays neutral with regard to jurisdictional claims in published maps and institutional affiliations.

Copyright: (c) 2021 by the author. Licensee MDPI, Basel, Switzerland. This article is an open access article distributed under the terms and conditions of the Creative Commons Attribution (CC BY) license (https:// creativecommons.org/licenses/by/ $4.0 /)$.
Department of Pharmacy, University “G. d'Annunzio" of Chieti-Pescara, Via dei Vestini 31, 66100 Chieti, Italy; marcello.locatelli@unich.it

In this issue of the Journal "Analytica", there is a selection of accepted articles, after peer-review process, in which the great importance that Analytical Chemistry plays in the field of Applied Sciences and the vastness of the implications in the various sectors are highlighted. In particular, it can be seen how Analytical Chemistry and the powerful statistical data processing tools are able not only to lead to robust procedures for the characterization of biological systems, but also to the development of innovative approaches for analysis in the environmental field and in the characterization of complex systems. In particular, it is possible to understand how these tools are now in daily use, even if they go unnoticed by most. The research and development of new technologies capable of providing answers to analytical questions is of fundamental importance and, in the field of Chemistry, certainly Applied Analytical Chemistry plays a prominent role. In fact, it exploits the knowledge and insights of Theoretical Sciences and puts them into practice in order to improve the state of the art, the applications, and the impact on all human activities. In this context, the developments on both instrumental procedures, but above all of sampling and sample treatment, which have witnessed a real exponential increase in both methods and devices in recent years, are fully inserted. Of particular importance is the miniaturization process, which has allowed the evaluation and study of biological processes that were previously unattainable, as well as the application of statistical, and chemometric principles in the methodology optimization process, and has made it possible to optimize several parameters at once without having to conduct the classic one variable at time (OVAT) procedures.

In these areas, the Analytical Chemist plays a fundamental role as the only specialist able to correctly apply and fully exploit the potential of these procedures/innovations/ techniques. It should also be emphasized that, given the complexity of the systems under study, continuous comparison and dialogue with other experts from other application fields is necessary in order to optimize information and arrive at the correct resolution of the problem.

In my opinion, this is all the more evident if, in addition to the articles themselves, attention is paid to the list of authors and co-authors. In all the Journals, a "mixture" of expertise necessary and fundamental for the correct analysis, processing and interpretation of the results is observed increasingly. The expanding mix of expertise necessary for the study of a phenomenon shows how fundamental it is to be able to "speak" the same language and to be able to compare and report data in an organic and coherent way. In fact, nowadays, in addition to the challenges facing the Analytical Chemist and more generally the Scientific Community, a very important one is that of interfacing with "non-analytical" research fields, trying to use a "universal" language. In this sense, the International Guidelines and the correct definitions of the parameters must always be used as the basis for all studies. The selection of the articles included in this issue shows how, through a "common" language, it is possible to obtain extremely powerful procedures, methodologies, and applications.

Funding: This research received no external funding. 